\title{
Intervenção precoce e a participação da família: relato de profissionais de APAES
}

Early intervention and family participation: APAES' professionals report

APAES' professionals report Intervención temprana y participación de la familia.

\section{* Tahena Silva Ferreira}

Mestre pela Universidade Estadual Paulista Júlio de Mesquita Filho (UNESP), São Paulo, São Paulo, Brasil. tahena@gmail.com - http://orcid.org/0000-0002-6089-9498

\section{** Alessandra Pereira Falcão}

Doutoranda pela Universidade Estadual Paulista Júlio de Mesquita Filho (UNESP), São Paulo, São Paulo, Brasil.

alepfalcao@hotmail.com

\section{*** Ana Paula de Oliveira}

Doutoranda pela Universidade Estadual Paulista Júlio de Mesquita Filho (UNESP), São Paulo, São Paulo, Brasil.

ana_paula_apo@hotmail.com

\section{**** Olga Maria Piazentin Rolim Rodrigues}

Professora Adjunta pela Universidade Estadual Paulista Júlio de Mesquita Filho (UNESP), São Paulo, São Paulo, Brasil.

olgarolim29@gmail.com

\section{***** Veronica Aparecida Pereira}

Professora pela Universidade Federal da Grande Dourados, Dourados, Mato Grosso do Sul, Brasil. veronica.ufgd.tci@gmail.com

Recebido em 27 de março de 2018

Aprovado em 11 de dezembro de 2018

Publicado em 06 de maio de 2019

\section{RESUMO}

O presente estudo teve por objetivo descrever, a partir do relato de diferentes profissionais, como é a participação da família em serviços de Intervenção Precoce (IP) oferecidos por Associações de Pais e Amigos dos Excepcionais (APAES) do Estado de São Paulo, investigar quais ações essas instituições promovem para a integração desse público em seus atendimentos e se há continuidade das intervenções no ambiente domiciliar. Participaram vinte e três profissionais de diferentes áreas atuando como responsável pelo serviço de IP de 22 APAES do estado de São Paulo. Os profissionais responderam um questionário online para coleta de seus dados sociodemográficos e informações referentes 
à participação das famílias no serviço de IP que versavam sobre: principais atividades/funções executadas pela família na IP; quais familiares participam da IP; a frequência dos atendimentos oferecidos; o perfil das famílias participantes; as dificuldades identificadas para a continuidade das intervenções propostas e os desdobramentos desse serviço. Os resultados apontaram que os profissionais valorizam a participação da família e atribuem a essa participação o progresso da criança. Todavia, para $67 \%$ deles o atendimento à família é feito quando os profissionais identificam necessidades específicas da criança. O não envolvimento familiar é atribuído ao pouco tempo que a família dispõe para a realização do que foi orientado pelos profissionais. Tais resultados, provavelmente, se devem pelo atendimento não se caracterizar como centrado na família. Para futuros estudos sugere-se investigar um maior número de instituições que realizam o processo de IP cujos resultados podem confirmar ou não os obtidos neste estudo.

Palavras-chave: Família; Educação Especial; Intervenção precoce.

\section{ABSTRACT}

This study aimed to describe, based on reports from different professionals, the participation of family members in Early Intervention (EI) Services offered by Associations of Parents and Friends of the Exceptional (APAES) in the State of São Paulo, and to investigate what actions these institutions promote to foster the integration of this public to their treatment sessions, and whether there is continuity of the interventions at the patients' homes. The participants were twenty-three professionals from different areas acting as responsible for IP service 22 APAES the state of São Paulo. These professionals answered an online survey in order to provide sociodemographic data and information regarding family members' participation in El services regarding: main activities/ functions executed by family members in El, which family members participate in El, frequency of the sessions, profile of the participating families, identified difficulties for the continuance of the proposed interventions and the results obtained by this service. The results of the study point out that the professionals value the participation of family members and that they attribute to this participation the improvement of the children. However, to the $67 \%$ of them sessions involving family members are made when the professionals identify specific needs in the child. Family non-involvement is attributed to the lack of available time to do what was suggested by the professionals. Such results are probably due to treatment not being familycentred. For further studies it is suggested to investigate a greater number of institutions that do the El process whose results may or may not confirm those obtained in this study.

Keywords: Family; Special Education; Early intervention.

\section{RESUMEN}

El presente estudio tuvo por objetivo describir, a partir del relato de diferentes profesionales, como es la participación de la familia en servicios de Intervención temprana (IT) ofrecidos por Asociaciones de Padres y Amigos de los Excepcionales (APAES) del Estado de São 
Paulo, investigar que acciones esas instituciones promueven para la integración de este público en sus atendimientos y si hay continuidad de las intervenciones en el ambiente domiciliar. Participan veintitrés profesionales de diferentes áreas actuando como responsables del servicio de IT de 22 APAES del Estado de São Paulo. Los profesionales respondieron un cuestionario online para la colecta de datos sociodemográficos y informaciones referentes a la participación de las familias en el servicio de IT que versaban sobre: principales actividades/ funciones ejercidas por la familia en la IT, que familiares participaban en la IT, la frecuencia de los atendimientos ofrecidos, el perfil de las familias participantes, las dificultades identificadas para la continuidad de las intervenciones propuestas y los resultados de este servicio. Los resultados señalaron que los profesionales valorizan la participación de la familia y atribuyen a esa participación el progreso del niño. Sin embargo, para el $67 \%$ el atendimiento a la familia se hace cuando los profesionales identifican necesidades específicas del niño. La no implicación familiar es atribuida al poco tiempo de que la familia dispone para la realización de lo que fue indicado por los profesionales. Tales resultados probablemente se deban a que el atendimiento no se caracteriza como centrado en la familia. Para futuros estudios se sugiere investigar un mayor número de instituciones que realizan el proceso de IT cuyos resultados pueden confirmar o no los obtenidos en este estudio.

Palabras clave: Familia; Educación Especial; Intervención temprana.

\section{Introdução}

Entre as diferentes perspectivas teóricas sobre o desenvolvimento humano, alguns autores propõem a compreensão do mesmo a partir de interações ambientais (família, escola, grupos e demais relações que o organismo possa ter). Bronfenbrenner (1996) em seu modelo bioecológico aponta que durante o desenvolvimento humano acontecem processos de interações recíprocas e complexas entre o ser humano e seu ambiente. Nesta perspectiva, são quatro os núcleos de desenvolvimento: contexto, processo, pessoa e tempo. O contexto é a relação entre os quatro níveis ambientais (sistemas) microssistema, mesossistema, exossistema e macrossistema. Os processos são as formas particulares de relação entre o organismo e o ambiente ao longo do tempo (forma, força, conteúdo e direção). A pessoa tem suas características determinadas biopsicologicamente e o tempo envolve mudanças e continuidades que ocorrem ao longo do ciclo vital. Para Sameroff (2009), em seu modelo transacional, a criança modifica seu ambiente e é modificada pelo mesmo. Para o autor, o desenvolvimento é um processo dinâmico que envolve as mudanças ocorridas ao longo do tempo entre as interações da criança e do seu ambiente. Outra contribuição para compreensão das interações ambientais é apresentada por Skinner 
(1953/2003) que aponta o comportamento como interação entre organismo e ambiente, de forma bidirecional e, assim como Sameroff (2009) indica que o organismo modifica o ambiente é modificado pelo mesmo. As teorias do desenvolvimento são unânimes em enfatizar a individualidade de cada pessoa e apontar que, tanto os fatores genéticos quanto ambientais, irão influenciar o desenvolvimento humano ao longo de sua vida (SKINNER, 1953/2003; BRONFENBRENNER, 1996; KAIL, 2004; SAMEROFF, 2009; BEE; BOYD, 2011; PAPALIA; OLDS; FELDMAN, 2013).

As interações do bebê se iniciam ainda no período gestacional por meio das conexões fisiológicas entre o organismo materno e da criança. Contudo, elas não se restringem às interações orgânicas, uma vez que, ao saberem da gestação, os pais começam a fazer planos sobre as características fisionômicas, psicológicas ou até mesmo comportamentais de seus filhos. Ponderam, também, sobre a série de mudanças e adaptações necessárias e sobre os novos papéis que terão que desempenhar, incluindo uma reestruturação nas relações conjugais, familiares e sociais (FLORES, 2013).

A chegada de um bebê que apresenta algum tipo de deficiência pode se configurar em um fator estressor para família, pois além das mudanças naturais advindas com o nascimento de um novo integrante, pode requerer a aprendizagem de uma série de habilidades e competências mais específicas e intensas devido ao desenvolvimento atípico que a criança pode apresentar (PEREIRA-SILVA; OLIVEIRA; ROOKE, 2015). Por ser o primeiro ambiente com o qual a criança interage por meio das relações estabelecidas com os pais e irmãos, a família torna-se um importante preditor para um desenvolvimento infantil saudável (BEE; BOYD, 2011). Já nos primeiros anos de vida a interação com pares pode estabelecer comportamentos importantes para o repertório da criança, principalmente de socialização, elemento essencial ao desenvolvimento cognitivo. Quando presentes no ambiente familiar, as práticas psicossociais desfavoráveis podem resultar em prejuízos à criança, podendo incidir sobre funções relacionadas à memória, a linguagem, as habilidades sociais e no seu desenvolvimento integral (BRAGANÇA; ALVES; LEMOS, 2014). Desta forma, o ambiente familiar poderá configurar-se como um fator de proteção ou risco ao desenvolvimento.

O fator de proteção pode ser observado quando os pais apresentam práticas parentais educativas positivas. Gomide (2003) ressalta os comportamentos dos pais no uso adequado da atenção e distribuição de privilégios, a distribuição contínua e segura de afeto, 
o estabelecimento de regras, o acompanhamento e supervisão das atividades escolares e de lazer e o ensino do comportamento moral que implica no desenvolvimento do senso de justiça, da empatia, da responsabilidade, da generosidade, do trabalho e no conhecimento do certo e do errado. Garmezy (1985) classificou três categorias de fatores de proteção: a) atributos disposicionais da criança que envolvem orientação social positiva, autonomia, autoestima e preferências; b) características da família como coesão, ausência de discórdia, afetividade e ausência de negligência e, c) fontes de apoio individual ou institucional disponíveis para a criança e a família como o relacionamento da criança com pares e pessoas de fora da família, suporte cultural e atendimento. Guralnick (1998) destacou três padrões que são essenciais na interação da família: a qualidade da interação dos pais com a criança; a forma como a família fornece à criança experiências apropriadas e diversas com os ambientes físico e social ao seu redor e, a maneira pela qual a família garante segurança e saúde para a criança.

Voivodic e Storer (2002) apontam que a família é o contexto natural para a criança receber auxílio e crescer. A família identifica as suas necessidades e promove, a partir de sua interação e das experiências vividas, o aumento do repertório comportamental da criança, imprescindível para o desenvolvimento saudável. De outra forma, práticas de negligência, abuso físico ou psicológico e tantas outras formas de violência podem apresentar-se como fatores de risco.

Nesse sentido, os pais exercem um papel fundamental no desenvolvimento integral e saudável da criança. Especialmente com crianças de desenvolvimento atípico, ou com risco para o desenvolvimento, ao entenderem melhor o diagnóstico da criança e ao se envolverem nos cuidados de seus filhos, esses pais passam a dispor de habilidades e aprendizados que serão essenciais para estimular o bebê desde os primeiros dias de vida (SERRANO; CORREIA, 2002; DE ALMEIDA, 2004). Além disso, Turchiello (2017) afirma que manter a família em interação em diferentes espaços, possibilita dotá-la de saberes, o que a posiciona, também, como agente de inclusão.

A importância de uma intervenção ocorrer logo nos primeiros meses de vida, tanto por profissionais de saúde quanto pela própria família, se pauta no fato de que o atendimento em idade precoce é crucial para o desenvolvimento físico, cognitivo e emocional da criança (GIFFORD-SMITH; BROWNELL, 2003). Nesse contexto, torna-se fundamental avaliar e 
intervir, o mais cedo possível, junto às famílias das crianças que manifestam algum tipo de alteração estrutural ou funcional (BAIRRÃO; DE ALMEIDA, 2003; PEREIRA, 2009).

A Intervenção Precoce (IP) é uma modalidade de trabalho que tem como uma de suas principais características dirigir seus esforços para os anos iniciais do desenvolvimento infantil, o contexto familiar em que este ocorre e as interações familiares estabelecidas. Essa prática envolve um conjunto de profissionais de saúde e seus saberes, tendo a articulação entre essas diferentes abordagens para caracterização e diagnóstico. Contudo, em alguns contextos e processos de intervenção, a dimensão etiológica pode ser pouco útil ou a dimensão sindromática pode nem ser considerada, visto que as ações, competências e participações efetivas da criança e sua família serão determinantes do trabalho que será realizado (FRANCO; MELO; APOLONIO, 2012).

Serrano e Correia (2002) apontam que a IP se refere a um conjunto de serviços multidisciplinares que visa promover saúde e bem-estar a crianças com idade entre zero e cinco anos e sua família, reforçando suas competências emergentes, minimizando os atrasos desenvolvimentais, atenuando disfunções, prevenindo deteriorações funcionais, potencializando as capacidades parentais adaptativas e o funcionamento da família em geral. Essa definição esclarece a importância dos primeiros anos de vida para o desenvolvimento e a flexibilidade que eles proporcionam para as intervenções profissionais.

Historicamente, a IP tem sido pautada no modelo multidisciplinar, em que cada profissional de saúde tem o domínio das informações de sua área e, com base nisso, toma decisões e utiliza recursos considerados mais apropriados para aquela criança com desenvolvimento atípico transmitindo, posteriormente, orientações a família (FERNANDES; SERRANO; BARBA, 2016). Entretanto, atualmente tem-se difundido a ideia de colaboração para melhorar as competências da família em lidar com as questões de IP, baseada nas potencialidades da pessoa, nos recursos da comunidade e centrado na família. Com isso, segundo as autoras, é enfatizado um modelo horizontalizado e não hierárquico, onde os profissionais apoiam as decisões das famílias.

Os programas de IP envolvem diversos contextos, a participação de diversas áreas, a coordenação dos serviços oferecidos, a colaboração entre instituições e o apoio a uma população heterogênea de crianças e famílias. Atualmente, a atenção é concentrada na importância das interações dinâmicas que se estabelecem entre a criança e o meio que a 
cerca e, também, para os impactos diretos e indiretos que esses diferentes contextos têm em seu desenvolvimento (DE ALMEIDA et al., 2011).

Diversos autores enfatizam a importância da IP ser focalizada nas necessidades da criança e de sua família (KUMPFER; ALVARADO 2003; WILLIAMS; AIELLO, 2004, PELCHAT; LEFEBVRE; LEVERT, 2007). Os benefícios da participação da família se refletem em uma melhor compreensão da deficiência, no bem-estar tanto no relacionamento conjugal quanto nas práticas parentais e nas percepções consideradas mais positivas sobre vários aspectos da vida. Neste contexto são descritos alguns estudos que relatam práticas de IP ou intervenções com familiares.

Lapa e Almeida (2015) descreveram as representações sociais de 18 técnicas e 24 famílias sobre a participação e direito das crianças que participam de IP em Portugal. Segundo o relato das profissionais, a família assume um papel de participação ativa ao longo de toda a intervenção. No relato das famílias, a participação das crianças é importante, contudo, na prática, as decisões dos adultos prevalecem, uma vez que elas não sabem o que é melhor para seus filhos, cabendo aos pais esse papel.

Da Silva e Aiello (2012) avaliaram se uma intervenção direcionada aos pais de bebês com síndrome de Down alterariam padrões de interação dos pais com o bebê. A intervenção constituiu em o psicólogo fornecer orientações sobre como estimular a criança a partir de treino de comportamentos para o desenvolvimento do bebê. Participaram cinco famílias (pai, mãe e bebê), mas somente os pais passaram pela intervenção. Os resultados apontaram para aumento na frequência de comportamentos positivos de pais e bebês.

Melo e Tadeu (2014) descreveram um procedimento de IP realizado em um Centro Social com uma criança de cinco anos que apresentava hérnia umbilical e vários episódios de otites e sua mãe. Com base nas necessidades apontadas pela família delineou-se um plano de intervenção centrado na família, considerando o modelo bioecológico e transacional. Para a criança foram elaboradas estratégias que foram trabalhadas em contexto escolar. A mãe participou de reuniões periódicas com a educadora com a finalidade de elaborar e avaliar o plano individualizado de apoio à família, além de usufruir dos diversos serviços que o centro social dispõe, contemplando estratégias nos domínios da saúde, financeiro e habitacional. Observaram-se resultados positivos no desenvolvimento da criança e nos comportamentos da mãe face às estratégias planificadas. Segundo as autoras, foi possível prevenir e melhorar o desenvolvimento da 
criança e identificar os fatores de risco no seu ambiente. A intervenção nas rotinas e nos contextos da família permitiu compreender e ir ao encontro dos seus valores e estilos de vida e, desta forma, melhorar a qualidade da unidade familiar e a sua inserção na comunidade.

Pichini et al. (2016) analisaram e compararam as percepções de pais e dos terapeutas sobre os efeitos da IP no desenvolvimento de seus filhos e no cuidado aos mesmos, bem como suas percepções referentes à evolução dos filhos e perspectivas futuras, após seis meses de intervenção. $O$ estudo foi composto por nove crianças com idades entre dois anos e um mês e quatro anos e sete meses, sendo três meninas e seis meninos, com distúrbios de linguagem, associados ou não a transtornos do desenvolvimento. Nas intervenções foram criadas estratégias de inclusão dos familiares no processo terapêutico, tais como o atendimento conjunto pais-bebê e a possibilidade de apoio psicológico aos pais. Nos atendimentos conjuntos articularam-se cenas que oscilaram durante a sessão, a saber: pais-terapeuta; bebê-pais; bebê-terapeuta e bebê-pais-terapeuta. Acerca da evolução da criança nos aspectos do desenvolvimento linguístico, motor, social e psíquico os resultados mostraram que, em relação à comunicação e aspectos gerais do comportamento, todas as mães reconheceram as evoluções dos filhos, sobretudo, em termos de compreensão e expressão orais. As mães também relataram aumento por parte da criança, na participação das atividades cotidianas familiares, além de relatarem que a entrada de um profissional de referência é vista como um marco no desenvolvimento do filho e importante como suporte para a família. Pode-se observar concordância entre as percepções parentais e terapêuticas acerca da evolução dos aspectos do desenvolvimento linguístico e motor em sete dos casos. Em termos social e psíquico das crianças, em dois casos não houve concordância, pois, os familiares demonstraram percepção inadequada dos avanços da criança e expectativas de difícil realização no futuro das crianças.

Carr et al. (2016) examinaram a relação entre os fatores demográficos familiares, o atendimento e a adesão ao tratamento de crianças com autismo de dois a cinco anos por seus cuidadores e como essa relação interfere nos resultados. Participaram 147 díades de cuidador-criança de uma população de baixa renda que foram distribuídas aleatoriamente para o módulo de intervenção individual ou para o módulo de intervenção em grupo. A distribuição da intervenção entre os grupos diferiu na maneira como o conteúdo da intervenção foi divulgado às famílias. Os cuidadores na condição individual foram treinados 
ativamente por um clínico durante sessões individuais em suas casas e com a criança. Aos cuidadores na condição de grupo foi apresentado o conteúdo da intervenção em formato de conferência com outros pais, sem a presença das crianças. Para ambas as condições o tratamento tinha o mesmo conteúdo e teve duração de três meses. $O$ atendimento ao tratamento, a adesão e o resultado (tempo gasto no engajamento) foram as principais variáveis de resultado. A participação foi significativamente prevista pelo estado socioeconômico, local da intervenção e condição de tratamento. As famílias no módulo de intervenção individual tiveram níveis mais baixos de adesão ao tratamento, que foi significativamente previsto pelo estresse do cuidador e menor quociente de inteligência não verbal da criança, porém tiveram interações significativamente mais longas de engajamento no pós-teste (envolvimento das díades cuidador-criança na mesma atividade durante 10 minutos), que foi significativamente predita por uma interação entre atendimento e condição do tratamento. Em geral, os resultados enfatizam a importância de considerar variáveis demográficas quando se considerar barreiras ao atendimento e adesão ao tratamento.

Diante da importância do envolvimento da família nos programas da IP, o presente trabalho teve por objetivos: a) descrever, a partir do relato de diferentes profissionais, como é a participação da família em serviços de IP oferecidos por Associações de Pais e Amigos dos Excepcionais (APAES) do Estado de São Paulo, b) investigar quais ações essas instituições promovem para a integração desse público em seus atendimentos e se há continuidade das intervenções propostas para os filhos no ambiente domiciliar.

\section{Método}

\section{Procedimento de Coleta de Dados}

A partir dos contatos disponíveis no site da Federação das APAES do Estado de São Paulo (FEAPAES-SP), 303 APAES foram contatadas via telefone, 184 indicaram a existência de serviços de IP e interesse em participar da pesquisa. Os responsáveis pelo serviço de IP receberam um e-mail contendo os objetivos da pesquisa e um questionário a ser respondido. Aqueles que manifestaram interesse em participar ratificaram a sua anuência com a assinatura do Termo de Consentimento Livre e Esclarecido (TCLE) de acordo com a Resolução no 510 , de 7 de abril de 2016 do CONEP. O prazo para o retorno foi de 15 dias após o envio. Houve retorno de 22 instituições. 


\section{Participantes}

Participaram vinte e três profissionais, entre 24 a 63 anos (média=41,71 anos, $\mathrm{DP}=11,27$ ) de diferentes áreas, sendo seis Psicólogos, quatro Fisioterapeutas, quatro Terapeutas Ocupacionais, três Pedagogos, dois Assistentes Sociais, um Fonoaudiólogo, um Enfermeiro e um Educador Especial. Um participante não informou a área e dois dos profissionais eram da mesma instituição. Os profissionais respondentes na ocasião da pesquisa atuavam como coordenador ou responsável pelo serviço de IP das vinte e duas APAES, situadas em diferentes cidades do estado de São Paulo.

\section{Instrumento}

Foi elaborado para esta pesquisa o "Instrumento para caracterização da participação da família em programas de intervenção precoce" que continha perguntas sociodemográficas e área escolar, tempo de atuação na APAE, no serviço de IP e principais atividades/funções executadas na APAE e na IP. O questionário também continha 16 questões fechadas que versavam sobre: as principais atividades/funções executadas pela família na IP; quem e em que momento participa da IP e a frequência dos atendimentos oferecidos; o perfil das famílias participantes; as dificuldades identificadas para a continuidade das intervenções propostas e os resultados desse serviço.

\section{Procedimento de Análise de Dados}

A partir dos dados coletados por meio do questionário, as respostas fornecidas pelos profissionais das APAES foram organizadas em categorias, em forma de tabelas e planilhas. Foram estruturadas três categorias, sendo: a) caracterização do público atendido: número de crianças atendidas pela APAE (por faixa etária) e faixas etárias com previsão de atendimento em IP; b) avaliação da participação da família - periodicidade, motivos para intervenção domiciliar e dificuldades encontradas; e c) motivos para envolvimento familiar, na visão dos profissionais. O questionário, estruturado com questões fechadas, continha também espaço para outras informações relevantes, as quais foram acrescidas às tabelas. A Tabulação foi organizada a partir do cálculo das frequências absolutas (FA) e frequências relativas (FR) para cada categoria.

\section{Resultados}

A caracterização do público atendido e previsão das faixas etárias com elegibilidade para IP encontra-se apresentada nas Tabelas 1 e 2. A partir dos questionários respondidos 
pelos responsáveis pela IP em cada uma das 22 APAES, pode-se constatar que atualmente são atendidas 1276 crianças nas instituições, sendo 539 (42\%) crianças de 49 meses ou mais, $242(19 \%)$ de 25 a 36 meses, 213 (17\%) de 13 a 24 meses, $187(15 \%)$ de 37 a 48 meses e $95(7 \%)$ crianças de 0 a 12 meses, conforme mostra a Tabela 1.

Tabela 1- Número de crianças atendidas em cada faixa etária nos serviços de IP

\begin{tabular}{|l|c|c|}
\hline \multicolumn{3}{|c|}{ Crianças atendidas nas APAES } \\
\hline Idade & FA & FR\% \\
\hline 0 a 12 meses & 95 & 7 \\
\hline 13 a 24 meses & 213 & 17 \\
\hline 25 a 36 meses & 242 & 19 \\
\hline 37 a 48 meses & 187 & 15 \\
\hline de 49 meses ou mais & 539 & 42 \\
\hline Total & 1276 & 100 \\
\hline
\end{tabular}

A elegibilidade para atendimento nos serviços de IP oferecidos variou de três a seis anos, sendo que a maioria delas (36\%) previa o atendimento até seis anos, de acordo com a Tabela 2.

Tabela 2- Faixa etária prevista para atendimento nos serviços de IP

\begin{tabular}{|l|c|c|}
\hline Faixa etária das crianças & FA & FR\% \\
\hline 0 a 2 anos & 0 & 0 \\
\hline 0 a 3 anos & 6 & 27 \\
\hline 0 a 4 anos & 7 & 32 \\
\hline 0 a 5 anos & 1 & 5 \\
\hline 0 a 6 anos & 8 & 36 \\
\hline Total & 22 & 100 \\
\hline
\end{tabular}

Quanto aos atendimentos de IP, eles têm sido realizados em 17 APAES (77\%) prioritariamente com criança e cuidadores e em cinco APAES (22\%) somente com a criança. Em relação ao momento da participação dos cuidadores (pai e/ou mãe), prevaleceu que a participação acontece desde a triagem com 19 (68\%) respostas, seguida de que acontece nos atendimentos e continua em casa sete (25\%) e, dois (7\%) assinalaram que acontece desde o planejamento do atendimento. Os respondentes assinalaram mais de uma opção de resposta.

Sobre a periodicidade dos atendimentos oferecidos à família, 10 participantes (43\%) relataram que acontecem semanalmente, três (13\%) apontaram que são quinzenais, três 
(13\%) relataram que acontecem mensalmente, três (13\%) não oferecem atendimentos aos pais e, quatro (17\%) relataram que acontecem mais de uma vez na semana.

Em se tratando do atendimento à família (mãe/pai/cuidador) há atendimento somente para a mãe quando necessário em 15 (67\%) instituições, o atendimento a família é sempre associado ao atendimento da criança em 12 (48\%) e, para um (5\%) não há previsão de atendimento a família.

Quanto à participação da família durante as atividades desenvolvidas com a criança, 14 (54\%) responsáveis pela IP relataram que a família participa dos atendimentos dependendo do profissional que atende a criança, seis (23\%) relataram que a família não participa e aguarda na sala de espera, cinco $(19 \%)$ relataram que a família acompanha todas as atividades e um (4\%) relatou que a família se engaja nas atividades oferecidas.

Para 14 (64\%) participantes as intervenções de IP não são centralizadas na família, sendo exclusivamente dirigidas a criança e suas necessidades, enquanto oito (36\%) participantes relataram que as intervenções são, também, dirigidas à criança e à família.

Em 21 (95\%) APAES são propostas intervenções para mães ou famílias realizarem em casa e uma instituição (5\%) não faz essa proposta. Todavia, quanto as orientações à mãe/pai para a continuidade das intervenções em casa, 14 participantes (56\%) responderam que dependem exclusivamente das necessidades da criança em áreas específicas, para oito participantes (32\%) as orientações já são previstas no planejamento de todas as crianças e três participantes $(12 \%)$ consideram que depende do profissional que atende a criança.

Segundo todos os participantes, a mãe é o familiar mais engajado nas intervenções que são propostas. 
Tabela 3 - apresenta os motivos, segundo os profissionais, para a família dar continuidade na IP no ambiente domiciliar

\begin{tabular}{|c|c|c|c|c|c|c|}
\hline \multirow[t]{2}{*}{ Motivos } & \multicolumn{2}{|c|}{ Muito } & \multicolumn{2}{|c|}{ Relevante } & \multicolumn{2}{|c|}{ Pouco } \\
\hline & FA & $\mathbf{F R} \%$ & FA & $\mathbf{F R} \%$ & FA & $\mathbf{F R} \%$ \\
\hline $\begin{array}{l}\text { Acompanham os atendimentos } \\
\text { realizados e se interessam pelos } \\
\text { avanços no desenvolvimento da } \\
\text { criança }\end{array}$ & 7 & 44 & 8 & 50 & 1 & 6 \\
\hline $\begin{array}{l}\text { Dispõem de tempo para se } \\
\text { dedicarem ao desenvolvimento } \\
\text { da criança }\end{array}$ & 2 & 16 & 6 & 50 & 4 & 33 \\
\hline $\begin{array}{l}\text { Possuem maior instrução } \\
\text { educacional }\end{array}$ & 0 & 0 & 3 & 33 & 6 & 66 \\
\hline $\begin{array}{l}\text { Não apresentam dificuldades } \\
\text { financeiras }\end{array}$ & 2 & 22 & 3 & 33 & 4 & 44 \\
\hline $\begin{array}{l}\text { A estimulação dos filhos era uma } \\
\text { prática familiar desde o } \\
\text { nascimento da criança }\end{array}$ & 1 & 11 & 2 & 83 & 5 & 62 \\
\hline $\begin{array}{l}\text { Acompanham os atendimentos } \\
\text { multiprofissionais incluindo a } \\
\text { estimulação na rotina da criança }\end{array}$ & 1 & 8 & 8 & 66 & 3 & 25 \\
\hline $\begin{array}{l}\text { Tem apoio da família ou de } \\
\text { familiares }\end{array}$ & 1 & 10 & 7 & 70 & 2 & 20 \\
\hline Tem apoio do companheiro(a) & 1 & 12 & 7 & 87 & 0 & 0 \\
\hline $\begin{array}{l}\text { Compreendem as necessidades } \\
\text { da criança e entendem a } \\
\text { importância da IP para os } \\
\text { resultados desenvolvimentais }\end{array}$ & 10 & 50 & 7 & 35 & 3 & 15 \\
\hline $\begin{array}{l}\text { Perceberam melhoras no } \\
\text { desenvolvimento da criança com } \\
\text { sua participação }\end{array}$ & 5 & 31 & 9 & 56 & 2 & 12 \\
\hline $\begin{array}{l}\text { Tem um atendimento } \\
\text { individualizado e esclarecedor }\end{array}$ & 7 & 46 & 6 & 40 & 2 & 13 \\
\hline
\end{tabular}

Nota-se, pela Tabela 3, que para os profissionais, o motivo mais relevante para que a família dê continuidade na IP é porque compreendem as necessidades apresentadas pela criança e entendem a importância da IP para a otimização de seus resultados desenvolvimentais. Outro motivo de muita relevância foi porque tem um atendimento individualizado e esclarecedor pelo profissional que atende a criança. Segundo os mesmos, um dos motivos relevantes é porque acompanham todos ou grande parte dos atendimentos realizados, se interessam pelos avanços no desenvolvimento da criança e perceberam melhoras no desenvolvimento da criança com sua participação na estimulação precoce. Já 
os motivos pouco relevantes são o nível de instrução educacional, dificuldade financeira e acompanham os atendimentos multiprofissionais incluindo a estimulação na rotina da criança.

Tabela 4 - Dificuldades que implicam a continuidade da IP no ambiente familiar

\begin{tabular}{|c|c|c|c|c|c|c|}
\hline \multirow[t]{2}{*}{ Dificuldades } & \multicolumn{2}{|c|}{$\begin{array}{c}\text { Muito } \\
\text { relevante }\end{array}$} & \multicolumn{2}{|c|}{ Relevante } & \multicolumn{2}{|c|}{$\begin{array}{c}\text { Pouco } \\
\text { relevante }\end{array}$} \\
\hline & FA & FR\% & FA & $\mathbf{F R} \%$ & FA & FR\% \\
\hline 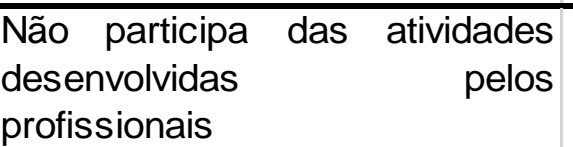 & 2 & 20 & 5 & 50 & 3 & 30 \\
\hline Sem tempo & 3 & 23 & 7 & 54 & 3 & 23 \\
\hline $\begin{array}{l}\text { Não aceita as dificuldades } \\
\text { apresentadas pela criança }\end{array}$ & 4 & 30 & 6 & 46 & 3 & 23 \\
\hline $\begin{array}{l}\text { Não percebe melhora no } \\
\text { desenvolvimento da criança }\end{array}$ & 1 & 16 & 3 & 50 & 2 & 33 \\
\hline $\begin{array}{l}\text { Formação educacional pode } \\
\text { dificultar a compreensão das } \\
\text { atividades propostas }\end{array}$ & 6 & 54 & 4 & 36 & 1 & 9 \\
\hline Dificuldades financeiras & 2 & 20 & 5 & 50 & 3 & 30 \\
\hline Não tem uma rede de apoio & 2 & 22 & 4 & 44 & 3 & 33 \\
\hline Não tem apoio do parceiro(a) & 2 & 28 & 3 & 43 & 2 & 28 \\
\hline $\begin{array}{l}\text { Não tem acesso à um } \\
\text { atendimento individualizado }\end{array}$ & 1 & 16 & 1 & 16 & 4 & 66 \\
\hline $\begin{array}{l}\text { Não compreende a importância } \\
\text { de atendimentos } \\
\text { multiprofissionais, optando por } \\
\text { atendimentos específicos }\end{array}$ & 0 & 0 & 2 & 28 & 5 & 71 \\
\hline $\begin{array}{l}\text { Acredita que a criança sempre } \\
\text { terá limitações e que uma } \\
\text { intervenção não irá auxiliar no } \\
\text { seu desenvolvimento }\end{array}$ & 1 & 12 & 2 & 40 & 5 & 62 \\
\hline $\begin{array}{l}\text { Leva a criança para a IP porque } \\
\text { foi encaminhado e para que } \\
\text { consiga ter acesso à benefícios } \\
\text { do governo }\end{array}$ & 1 & 10 & 3 & 30 & 6 & 60 \\
\hline
\end{tabular}

Observa-se pela Tabela 4 que uma das maiores dificuldades que implicam a continuidade da IP no ambiente familiar segundo os participantes é porque a mãe/família tem uma formação educacional que pode dificultar a compreensão das atividades propostas pelo profissional ou instituição. É visto como um dificultador relevante o fato da mãe/família não participar das atividades desenvolvidas pelos profissionais das APAES, por relatarem que as mães não têm tempo para realizar as atividades que são propostas para casa e 
porque parecem não aceitar as dificuldades apresentadas pela criança. Foi considerado pouco relevante o fato da mãe/família levar a criança para a estimulação precoce somente porque foi encaminhada e para que consiga ter acesso a benefícios do governo.

Tabela 5- Motivos pelos quais os resultados do desenvolvimento das crianças cujos pais se envolvem nos programas de IP são diferentes daqueles que não se envolvem

\begin{tabular}{|c|c|c|c|c|c|c|}
\hline \multirow[t]{2}{*}{$\begin{array}{l}\text { Motivos } \\
\end{array}$} & \multicolumn{2}{|c|}{$\begin{array}{l}\text { Muito } \\
\text { relevante }\end{array}$} & \multicolumn{2}{|c|}{ Relevante } & \multicolumn{2}{|c|}{$\begin{array}{c}\text { Pouco } \\
\text { relevante }\end{array}$} \\
\hline & FA & FR\% & FA & FR\% & FA & FR\% \\
\hline $\begin{array}{lr}\text { Os resultados } \\
\text { apresentados r pela } \\
\text { criança que é estimulada } \\
\text { em casa costumam ser } \\
\text { superiores aos que são } \\
\text { estimuladas apenas na } \\
\text { instituição }\end{array}$ & 13 & 81 & 1 & 6 & 2 & 12 \\
\hline $\begin{array}{l}\text { Os pais que estimulam a } \\
\text { criança também em } \\
\text { ambiente familiar dão } \\
\text { mais autonomia para ela, } \\
\text { acreditando que são } \\
\text { capazes de contribuir em } \\
\text { seu desenvolvimento }\end{array}$ & 8 & 50 & 8 & 50 & 0 & 0 \\
\hline $\begin{array}{lr}\text { Os pais respeitam o } \\
\text { trabalho realizado } & \text { pelo } \\
\text { profissional de } & \text { IP } \\
\text { permitindo que } & \text { as } \\
\text { orientações } & \text { exercícios } \\
\text { necessários } & \text { sejam } \\
\text { realizados com } & \text { sucesso }\end{array}$ & 10 & 71 & 3 & 21 & 1 & 7 \\
\hline
\end{tabular}

A partir da Tabela 5 pode-se afirmar que, segundo os relatos dos responsáveis pelo IP, o desenvolvimento das crianças cujos pais se envolvem nos programas de IP é superior aos das que são estimuladas apenas na instituição e o respeito dos pais pelo trabalho realizado pelo profissional de IP permite que as orientações e exercícios necessários sejam realizados com sucesso.

\section{Discussão}

Ao relacionarmos a literatura da área com os resultados obtidos a partir dos questionários respondidos pelos responsáveis pela IP das APAES do estado de São Paulo, pode-se apontar a importância da participação dos pais nas intervenções com a criança 
para o alcance de melhores resultados no desenvolvimento delas (GOMIDE, 2003; BEE; BOYD, 2011; BRAGANÇA; ALVES; LEMOS, 2014; LAPA; ALMEIDA, 2015) além de promoverem a inclusão (TURCHIELLO, 2017). Os autores destacam que a participação da família é um importante preditor para o desenvolvimento da criança ao estimular comportamentos importantes para o seu repertório, sendo assim um fator de proteção para a criança. Os participantes afirmaram que os resultados apresentados pela criança que é estimulada em casa costumam ser superiores aos das que são estimuladas apenas na instituição. Também corrobora com esse dado a inserção das famílias na IP nas APAES, visto que $78 \%$ dos atendimentos são realizados prioritariamente com criança e cuidadores. E, em $95 \%$ das instituições são propostas intervenções para mães/família realizarem em casa.

O atendimento em IP nas APAES do Estado de São Paulo é realizado em sua maioria com crianças entre zero e cinco anos e $36 \%$ das crianças que passam pelo serviço tem entre 0 e 6 anos. Autores tem apontado a importância de a intervenção ocorrer já nos primeiros anos de vida para a obtenção de melhores resultados no desenvolvimento físico, cognitivo e emocional de crianças que manifestem algum tipo de alteração estrutural ou funcional (GURALNICK, 1998; GIFFORD-SMITH; BROWNELL, 2003; LAPA; ALMEIDA, 2015).

Há a necessidade de apoio aos pais durante a intervenção, visto que, além de aumentar a efetividade dos programas de IP, o atendimento às famílias pode propiciar uma melhor adaptação ao problema da criança, melhores práticas parentais e melhor relacionamento conjugal (KUMPFER; ALVARADO, 2003; WILLIAMS; AIELO, 2004; PELCHAT; LEFEBVRE; LEVERT, 2007). Todavia, apesar da importância do apoio às famílias os resultados apontaram que há atendimento somente para a mãe quando necessário em $67 \%$ das instituições. Na maioria das instituições, o atendimento a família é sempre associado ao atendimento da criança em $48 \%$ e para $5 \%$ não há previsão de atendimento a família. Além disso, para $64 \%$ das instituições as intervenções de IP não são centralizadas na família, sendo exclusivamente dirigidas a criança e suas necessidades.

Outro resultado que vai à contramão da literatura foi o da participação da família durante as atividades desenvolvidas com a criança. Dos responsáveis pela IP 54\% relataram que a família participa dos atendimentos dependendo do profissional que atende a criança, $23 \%$ relataram que a família não participa e aguarda na sala de espera, $19 \%$ 
relataram que a família acompanha todas as atividades e $4 \%$ relataram que a família se engaja nas atividades oferecidas. Fernandes, Serrano e Barba (2016) afirmaram que cada profissional de saúde tem o domínio das informações de sua área e, com base nisso, toma decisões e utiliza recursos considerados mais apropriados para aquela criança com desenvolvimento atípico, transmitindo, posteriormente, orientações à família. Os autores também apontam que se tem enfatizado um modelo horizontalizado em que os profissionais valorizem competências e potencialidades de cada um dos familiares e apoiem as decisões dos mesmos.

Os resultados também apontaram que as famílias que dão continuidade na IP em suas casas o fazem porque compreendem as necessidades apresentadas pela criança e entendem a importância da IP para o desenvolvimento de seu filho, dado observado também por Lapa e Almeida (2015). Descreveram também, que ao acompanhar os atendimentos, a família se interessa pelos avanços no desenvolvimento da criança além de perceber melhoras a partir de sua participação. Ressaltando que a família é capaz de identificar as necessidades da criança e promover aumento no repertório comportamental da mesma, os pais ao entenderem melhor o diagnóstico da criança e ao se envolverem nos cuidados de seus filhos passam a dispor de habilidades e aprendizados que serão essenciais para estimular o bebê desde os primeiros dias de vida (VOIVODIC; STORER, 2002; SERRANO, CORREIA, 2002; DE ALMEIDA, 2004). Em contrapartida, famílias que não participam das atividades desenvolvidas pelos profissionais das APAES, os responsáveis pelo serviço de IP, relataram não ter tempo para realizar as atividades que são propostas para casa e não aceitam as dificuldades apresentadas pela criança.

\section{Considerações finais}

A partir dos resultados, pode-se confirmar a importância de se inserir a família da criança com necessidades especiais a partir da triagem da criança que passará por atendimento. É prioritário incluir intervenções a serem realizadas em casa e acolhimento as necessidades dos pais/família quanto ao entendimento do diagnóstico da criança até demandas específicas de dos familiares.

A não inserção dos pais/cuidadores no processo de IP por parte dos profissionais ou dos próprios familiares pode acarretar em prejuízos para a criança ao passo que crianças as quais os familiares participam do processo apresentam melhores resultados em seu desenvolvimento. 
Entre as limitações do estudo está o pequeno percentual de instituições que responderam ao instrumento enviado. Outra dificuldade encontrada pelas autoras foi o reduzido número de artigos publicados encontrados referentes à IP, psicólogos e familiares. Visto a importância do tema, é imprescindível que se realizem novas pesquisas em que sejam incluídos os familiares, inclusive, com orientações a serem realizadas no ambiente familiar. Pesquisas que verificaram, do ponto de vista dos responsáveis pelo serviço, os benefícios da IP e as dificuldades encontradas para a participação efetiva dos pais e a posterior realização das orientações propostas pelos profissionais também poderiam auxiliar em uma maior adesão dos cuidadores no processo de IP.

Para futuros estudos sugere-se investigar um maior número de instituições que realizam o processo de IP, além de como a intervenção psicológica com pais de crianças que passam pelo processo de IP pode contribuir para o melhor desenvolvimento de seus filhos.

\section{Referências}

BAIRRÃO, J.; ALMEIDA, I. C. Questões actuais em intervenção precoce. Psicologia, Lisboa, v. 17, n. 1, p. 15-29, jan. 2003.

BEE, H.; BOYD, D. A criança em desenvolvimento. Porto Alegre: Artmed. 2011.

BRAGANCA, L. L. C.; ALVES, C. R. L.; LEMOS, S. M. A. Estudo do perfil comunicativo de crianças de 4 a 6 anos na educação infantil. Rev. CEFAC, São Paulo, v. 16, n. 4, p. 12731282, Aug. 2014.

BRONFENBRENNER, U. A ecologia do desenvolvimento humano. Porto Alegre: Artes Médicas.1996.

CARR, T. et al. The relationship between treatment attendance, adherence, and outcome in a caregiver-mediated intervention for low-resourced families of young children with autism spectrum disorder. Autism. n. 6, p. 643-652, 2016.

CONEP. Resolução no 510, de 7 de abril de 2016. Disponível em: http://conselho.saude.gov.br/resolucoes/2016/Reso510.pdf. Acesso em: 22 mar. 2017.

DA SILVA, N. C. B.; AIELLO, A. L. R. Ensinando o pai a brincar com seu bebê com síndrome de Down. Educar em Revista, n. 43, p. 101-111, 2012.

DE ALMEIDA, I. C. et al. Práticas de intervenção precoce baseadas nas rotinas: Um projecto de formação e investigação. Análise Psicológica, v. 29, n. 1, p. 83-98, 2011 
DE ALMEIDA, I. C. Intervenção precoce: Focada na criança ou centrada na família e na comunidade? Análise Psicológica, n. 1, p. 65-72, 2004.

FEAPAES-SP. A Federação - quem somos. Federação das APAES do Estado de São Paulo. http://www.feAPAESp.org.br/federacao.asp?id=1Acesso em 06 jul. 2017.

FERNANDES, P. R. S.; SERRANO, A. M. S. P. H.; BARBA, P. D. Diálogos sobre a intervenção precoce. Journal of Research in Special Educational Needs, v. 16, n. 1, p. 373-377, 2016.

FLORES, M. R. et al. Associação entre indicadores de risco ao desenvolvimento infantil e estado emocional materno. Revista CEFAC, n. 2, p. 348-360, 2013.

FRANCO, V.; MELO, M.; APOLÓNIO, A. Problemas do desenvolvimento infantil e intervenção precoce. Educar em Revista, p. 49-69, 2012.

GARMEZY, N. Stress-resistant children: The search for protective factors. Recent research in developmental psychopathology, v. 4, p. 213-233. Oxford: Pergamon, 1985.

GIFFORD-SMITH, M. E.; BROWNELL, C. A. Childhood peer relationships: Social acceptance, friendships, and peer networks. Journal of school psychology, v. 41, n. 4, p. 235-284, 2003.

GOMIDE, P. I. C.; DEL PRETTE, A.; DEL PRETTE, Z. A. P. Habilidades sociais, desenvolvimento e aprendizagem,

GURALNICK, M. J. The effectiveness of early intervention for vulnerable children: a developmental perspective. American Journal on Mental Retardation, n. 4, p. 319-345, 1998.

KAIL, R V. A criança. São Paulo: Prentice Hall, 2004.

KUMPFER, K L.; ALVARADO, R. Family-strengthening approaches for the prevention of youth problem behaviors. American Psychologist, n. 6-7, p. 457-465, 2003.

LAPA, M. S. F.; ALMEIDA, C. T. Participação das crianças em intervenção precoce: representações sociais de técnicas e famílias. Revista Educação Especial, Santa Maria, p. 459-472, maio 2015.4 IDisponível em: https://periodicos.ufsm.br/educacaoespecial/article/view/15830. Acesso em: 13 jul. 2017. doi:http://dx.doi.org/10.5902/1984686X15830.

MELO, A.; TADEU, B. Construção de um plano individual de intervenção precoce: um caso que justifica a intervenção centrada na família. Interacções, p. 176-193, 2014.

PAPALIA, D. E.; FELDMAN, R. D. Desenvolvimento Humano. Porto Alegre: Artmed, 2013. 
PELCHAT, D.; LEFEBVRE, H.; LEVERT, M. Gender differences and similarities in the experience of parenting a child with a health problem: Current state of knowledge. Journal of Child Health Care, n. 2, p. 112-131, 2007.

PEREIRA, A. P. S. Práticas Centradas na Família em Intervenção Precoce: Um Estudo Nacional sobre Práticas Profissionais. Tese (Doutorado). Especialização em Educação Especial, Universidade do Minho, Braga, 2009.

PEREIRA-SILVA, N. L.; DIAS OLIVEIRA, L.; ITAGIBA ROOKE, M. Famílias com adolescente com síndrome de Down: apoio social e recursos familiares. Avances en Psicología Latinoamericana, n. 2, p. 269-283, 2015.

PICHINI, F. S. et al. Percepção da família e do terapeuta sobre a evolução de crianças em uma abordagem interdisciplinar de intervenção precoce. Revista CEFAC, n. 1, p. 55-66, 2016.

SAMEROFF, A. The transactional model. American Psychological Association, 2009.

SERRANO, A. M.; CORREIA, L. M. Intervenção precoce centrada na família: uma perspectiva ecológica de atendimento. In: CORREIA, L. M.; SERRANO, A. M. (Orgs.). Envolvimento parental em intervenção precoce: das práticas centradas na criança às práticas centradas na família. Porto: Porto Editora, 2002.

SKINNER, B. F. Ciência e comportamento humano (J. C. TODOROV; R. AZZI, Trans.) São Paulo: Martins Fontes, 2003. (Trabalho original publicado em 1953).

TURCHIELLO, P. Analisando a produção da família de pessoas com deficiência nos discursos das políticas de inclusão. Revista Educação Especial, Santa Maria, p. 339-350, ago. 2017. Disponível em: https://periodicos.ufsm.br/educacaoespecial/article/view/24117. Acesso em: 12 set. 2017.

VOIVODIC, M. A.; STORER, M. R. S. O desenvolvimento cognitivo das crianças com síndrome de Down à luz das relações familiares. Psicologia: teoria e prática, v. 4, n. 2, p. 31-40, 2002.

WILLIAMS, L. C. A.; AIELLO, A. L. R. Empoderamento de famílias: o que vem a ser e como medir. In: MENDES, E. G.; ALMEIDA M. A.; WILLIAMS, L. C. A. Temas em Educação Especial: avanços recentes. São Carlos: Editora da UFSCar, 2004. p. 197-202.

\section{Correspondência}

Tahena Silva Ferreira - Universidade Estadual Paulista. Rua: R. Pamplona, 145 Cerqueira César. CEP: 01405-000. São Paulo, São Paulo, Brasil.

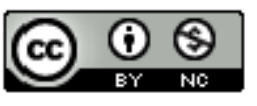

This work is licensed under a Creative Commons Attribution-NonCommercial 4.0 International (CC BY-NC 4.0) 